\title{
SISTEM PAKAR GANGGUAN DEPRESI PADA ANAK
}

\author{
Aldila Maharani ${ }^{1}$, Nilma $^{2}$, Ari Irawan $^{3}$ \\ ${ }^{1,2,3}$ Program Studi Informatika Fakultas Teknik dan Ilmu Komputer, \\ Universitas Indraprasta PGRI \\ Jalan Raya Tengah No.80, Kelurahan Gedong, Pasar Rebo, Jakarta Timur \\ Email :aㅣdilamhrn@gmail.com, ${ }^{2}$ nilma23juli@gmail.com, ${ }^{3}$ irawan@unindra.ac.id
}

\begin{abstract}
Abstrak
Sistem pakar merupakan salah satu aplikasi dari kecerdasan buatan (Artificial Intelegence). Gangguan psikologi pada anak banyak yang kurang disadari oleh orang tua dan pengajar yang menyebabkan terlambatnya penanganan pada anak. Tujuan dari penelitian dan dibuatnya aplikasi ini untuk membantu pengguna mendapatkan informasi mengenai gejala-gejala awal pada gangguan psikologis dan membantu mendiagnosa gangguan psikologi anak lebih awal. Aplikasi sistem pakar ini menggunakan Java sebagai Bahasa pemrograman dan menggunakan metode forward chaining. Sistem pakar ini mampu membantu dan mempermudah pengguna dalam memperoleh informasi gangguan psikologi pada anak khususnya mengenai depresi (depresi mayor, depresi persisten, gangguan bipolar dan depresi psikotis).
\end{abstract}

Kata Kunci: Sistem Pakar, Gangguan Psikologi, forward chaining

\section{Abstract}

The expert system is one of the applications of Artificial Intelligence (AI). Many children's psychological disorders are less noticed by parents and teachers, leading to delays in handling children. The purpose of the research and the design of this app is to help users get information about the initial symptoms of psychological disorders and help diagnose child psychological disorders early. This expert system application uses Java as a programming language and uses the forward chaining method. This expert system is able to help and facilitate users in obtaining information about psychological disorders in children, especially regarding depression (major depression, persistent depression, bipolar disorder and psychotic depression).

Keyword : expert system, psychology disease, forward chaining

\section{PENDAHULUAN}

Artificial Intelegence merupakan sub bidang pengetahuan yang khusus ditujukan untuk membuat software dan hardware sepenuhnya bisa menirukan beberapa fungsi otak manusia. Dengan demikian diharapkan komputer bisa membantu manusia di dalam memecahkan berbagai masalah yang lebih rumit.[1] Secara umum, Sistem pakar (Expert system) adalah sistem yang berusaha mengadopsi pengetahuan manusia ke komputer, agar komputer dapat menyelesaikan masalah seperti yang biasa dilakukan oleh para ahli[2].
Sistem pakar yang baik dirancang agar dapat menyelesaikan suatu permasalahan tertentu dengan meniru kerja dari para ahli. Dengan sistem pakar ini, orang awampun dapat menyelesaikan masalah yang cukup rumit yang sebenarnya hanya dapat diselesaikan dengan bantuan para ahli.[3].

Diharapkan dengan sistem ini, orang awam dapat menyelesaikan masalah tertentu baik 'sedikit' rumit ataupun rumit sekalipun 'tanpa' bantuan para ahli dalam bidang tersebut. Depresi tidak hanya terjadi pada orang dewasa. Anak- 
JURNAL NUANSA INFORMATIKA

Volume 15 Nomor 1, Januari 2021

anak dan remaja mungkin juga dapat mengalami depresi, yang sebenarnya merupakan penyakit yang dapat diobati. Depresi didefinisikan sebagai penyakit ketika perasaan tertekan dan mengganggu aktifitas seorang anak atau remaja untuk berfungsi normal. Sekitar 5\% dari anak-anak dan remaja di Indonesia menderita depresi pada suatu titik waktu tertentu. Anak-anak di bawah tekanan, pada saat belajar di sekolah, berada pada risiko yang lebih tinggi untuk depresi. Depresi juga cenderung ada di dalam keluarganya sendiri. [4]. Organisasi kesehatan dunia (WHO, 1974) menyebutkan bahwa $17 \%$ pasienpasien yang berobat ke dokter adalah pasien dengan depresi. [5]. Apabila gangguan psikologis terus dibiarkan dapat mengganggu tumbuh kembang anak tersebut. Dikarenakan belum adanya aplikasi yang dapat mendiagnosa gangguan psikologi berbasis java dan mengingat bahwa tenaga ahli dan jam praktek yang terbatas, sehingga pasien tidak dapat berkonsultasi dengan pakar kapan dan dimana saja, maka diperlukan sebuah sistem pakar yang dapat membantu peranan seorang pakar. Berdasarkan hal tersebut, maka peneliti membuat jurnal yang berjudul "Sistem Pakar Gangguan Depresi Anak".

Dalam melakukan penelitian tentang Sistem Pakar Gangguan Psikologi Pada Anak di PAUD Ananda, peneliti menggunakan bahan referensi dari berbagai sumber antara lain dari penelitian mahasiswa yang ada di Internet, dari jurnal mahasiswa yang ada di Internet serta beberapa buku penunjang untuk data-data yang dibutuhkan.

Penelitian relevan yang dilakukan (Doddy Satrya Perbawa, Wawan Laksito, Didik Nugroho 2012) yang berjudul "Sistem Pakar Perilaku Buruk Psikologis Pada Anak dengan Metode Forward Chaining",
p-ISSN : 1858-3911, e-ISSN : 2614-5405

https://journal.uniku.ac.id/index.php/ilkom

mengemukakan bahwa Membuat software yang berguna untuk membantu pengguna/masyarakat dalam konsultasi perilaku buruk psikologis pada anak sehingga dapat dilakukan tindakan pencegahan..

Penelitian relevan selanjutnya dilakukan oleh (Muhammad Hadi Sidiq, Aripin 2015) yang berjudul "Aplikasi Sistem Pakar Gangguan Perkembangan Psikologi Pada Anak Menggunakan Forward Chaining dan Teorema Bayes" menyatakan bahwa Perkembangan psikologi yang terganggu dapat menghambat proses pembelajaran pada anak dan dapat berdampak buruk pada perkembangan sosialnya, sehingga masalah gangguan perkembangan psikologi ini tidak boleh dianggap remeh sebagai masalah kecil[6]

\section{METODE PENELITIAN}

Metode penelitian yang digunakan pada Sistem Pakar Gangguan Psikologi Pada Anak ini menggunakan metode forward chaining. Metode forward chaining adalah teknik pencarian data yang dimulai dengan fakta-fakta yang diketahui, kemudian mencocokkan fakta tersebut dengan bagian if-then. Bila ada fakta yang cocok dengan if, maka aturan tersebut dapat dieksekusi. Bila sebuah aturan diekseskusi, maka sebuah fakta baru ditambahkan kedalam basis data. Setiap pencocokan akan diawali dari rule teratas dan setiap rule hanya akan dieksekusi sekali saja. Jika tidak ada rule yang dapat dieksekusi maka proses pencocokan akan berhenti [6] selain itu metode pengumpulan data yang penulis lakukan untuk mendapatkan data dalam melakukan penelitian ini adalah : Studi pustaka yaitu dengan membaca buku dan mengumpulkan data dari Internet serta artikel yang berhubungan dengan penelitian. Kemudian Studi Lapangan 
dengan cara Wawancara, observasi dan penelitian yang sejenis.

\section{HASIL DAN PEMBAHASAN}

Dalam hasil dan pembahasan penulis menggunakan flowchart dan uml. Flowchart Flowchart dapat diartikan sebagai suatu alat atau sarana yang menunjukkan langkah-langkah yang harus dilaksanakan dalam menyelesaikan suatu permasalahan untuk komputasi dengan cara mengekspresikannya ke dalam serangkaian simbol-simbol grafis khusus. [7]

\section{Flowchart Yang Diusulkan}

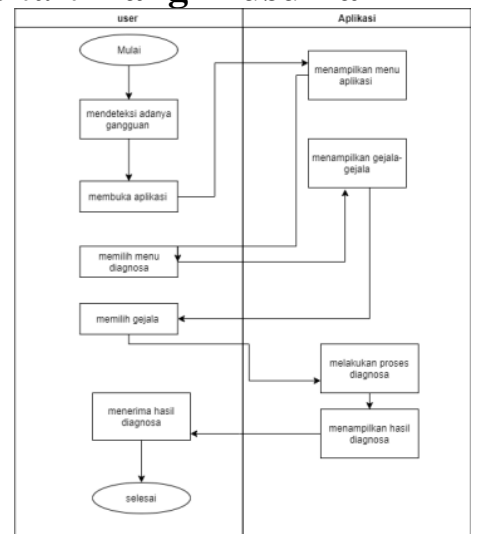

Gambar 1 flowchart yang diusulkan

Pada flowchart diatas menjelaskan apabila pengguna ingin melakukan konsultasi dengan melihat apabila anak memiliki indikasi gejala gangguan psikologis dapat membuka aplikasi. Lalu memilih menu konsultasi dan melakukan konsultasi dengan memilih gejala yang dirasa nampak pada anak lalu akan mendapatkan hasil dari konsultasi.

\section{Flowchart Menu Utama}

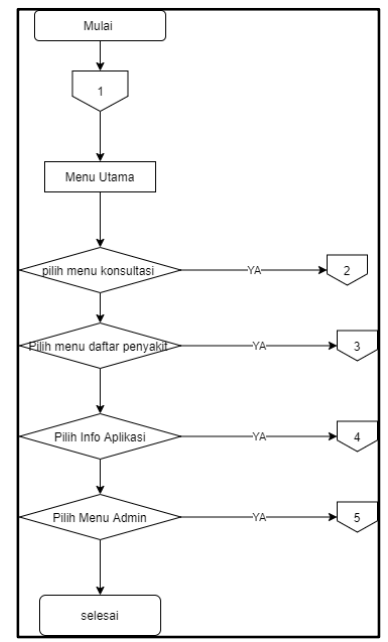

Gambar 2 flowchart Menu Utama

Pada gambar 2 menjelaskan mengenai alur pada menu utama. Alur menu utama. Dimana apabila pengguna memilih menu konsultasi akan diarahkan ke point nomor 2 yaitu menu konsultasi. Apabila pengguna memilih daftar penyakit akan diarahkan ke poin nomor 3 yaitu Menu daftar penyakit. Apabila pengguna memilih tentang aplikasi maka akan diarahkan ke nomor 4 yaitu tampilan tentang aplikasi. Apabila pengguna memilih menu admin maka akan diarahkan ke menu admin yaitu poin nomor 5 .

\section{Flowchart Menu Konsultasi}

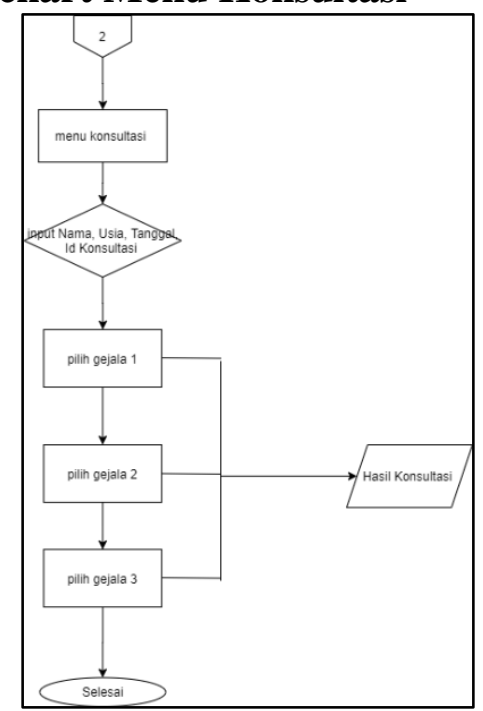

Gambar 3 flowchart Menu Konsultasi Pada gambar 3 yaitu flowchart Menu konsultasi menjelaskan alur mengenai 
pengguna saat ada di menu konsultasi pengguna akan diarahkan untuk memilih gejala yang dirasakan nampak pada pengguna.

\section{Flowchart Informasi Daftar Penyakit}

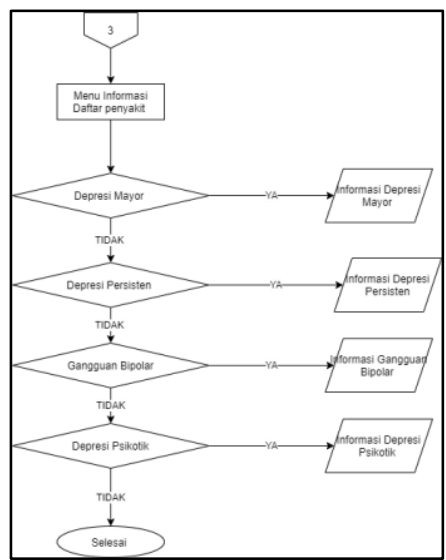

\section{Gambar 4 flowchart Menu Daftar Penyakit}

Pada gambar 4 yaitu flowchart daftar penyakit menjelaskan tentang alur ketika pengguna memilih menu daftar penyakit. Dimana pengguna dapat memilih penyakit yang ingin dilihat informasinya. Ketika pengguna memilih depresi mayor maka akan diarahkan ke halaman depresi mayor. Ketika pengguna memilih depresi persisten maka pengguna akan diarahkan ke halaman depresi persisten. Ketika pengguna memilih gangguan bipolar akan diarahkan ke halaman gangguan bipolar. Ketika pengguna memilih depresi psikotis maka akan diarahkan ke halaman depresi persisten.

\section{Tampilan Aplikasi}

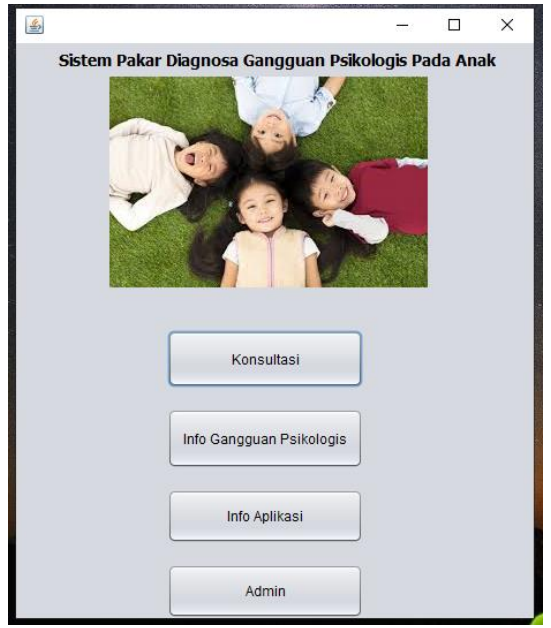

Gambar 5 Tampilan Menu Utama Gambar diatas merupakan gambar tampilan menu utama, dimana pada menu ini dimana pengguna dapat memilih menu konsulrasi, info gangguan psikologi dan info aplikasi serta memilih menu admin.

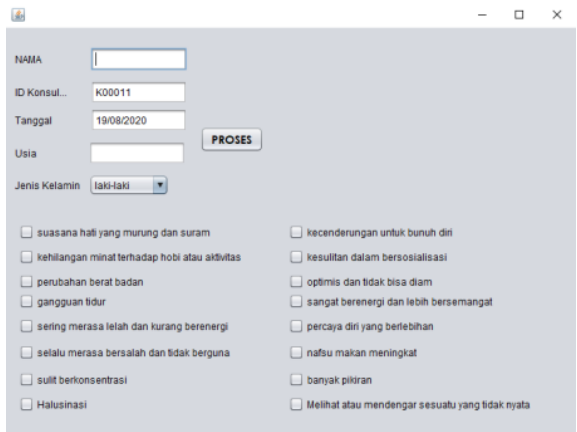

\section{Gambar 6 Tampilan Konsultasi}

Gambar diatas merupakan gambar tampilan menu konsultasi dimana pengguna harus memasukkan Nama, Usia dan memilih Jenis Kelamin. Sedangkan ID konsultasi dan Tanggal sudah terisi secara otomatis. Setelah pengguna memilih beberapa gejala yang di rasa, pengguna mengklik tombol proses. Setelah itu pengguna akan mendapatkan hasil dari diagnosa. 
JURNAL NUANSA INFORMATIKA

Volume 15 Nomor 1, Januari 2021

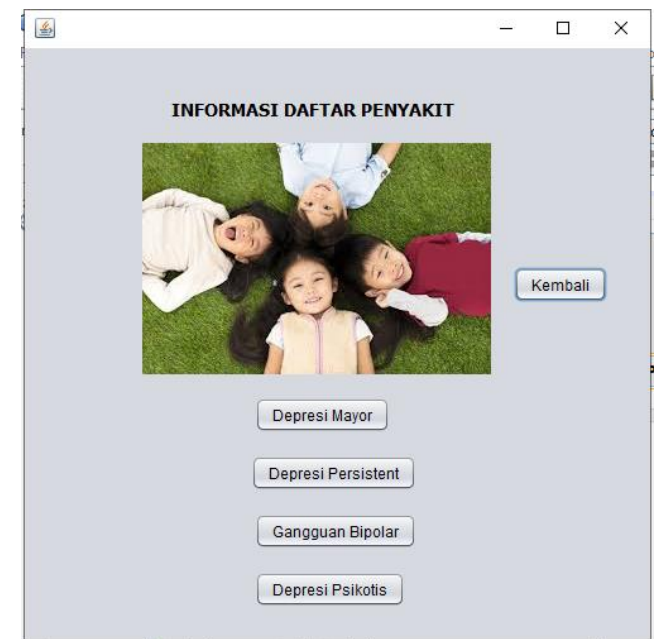

Gambar 7 Tampilan Informasi Daftar Penyakit

Gambar diatas merupakan gambar tampilan menu informasi daftar informasi daftar penyakit yang dapat dipilih oleh pengguna. Dimana informasi yang dipilih dapat berupa Depresi Mayor, Depresi Persisten, Gangguan Bipolar, Deprsi Psikotis.

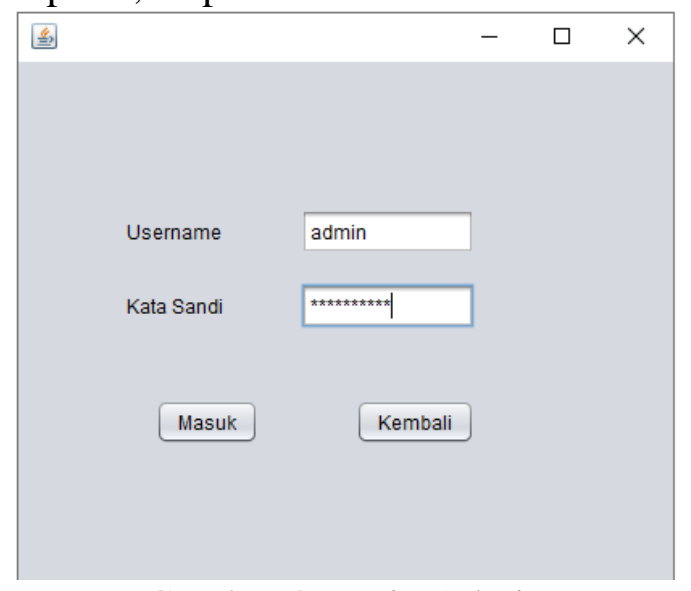

Gambar 8 Login Admin

Pada gambar 8 merupakan halaman login untuk admin, agar dapat mencetak laporan-laporan yang diinginkan.

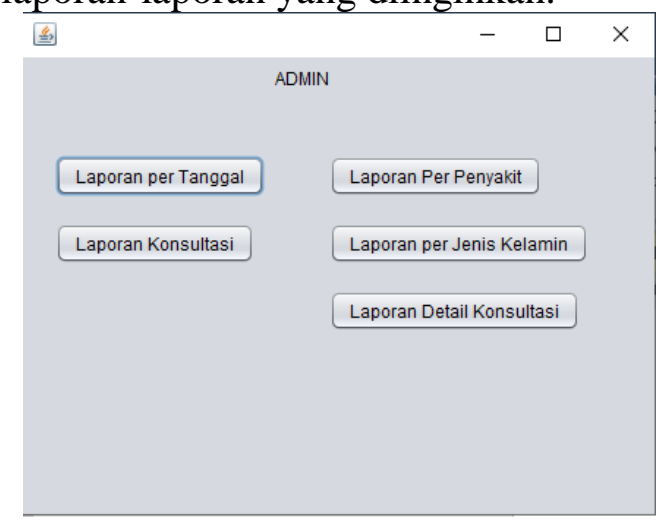

p-ISSN : 1858-3911, e-ISSN : 2614-5405

https://journal.uniku.ac.id/index.php/ilkom

\section{Gambar 9 Tampilan Menu Utama Admin}

Pada gambar 9 merupakan halaman menu utama Admin. Dimana halaman ini hanya bisa diakses oleh admin yang telah memasukkan username dan password yang sesuai. Admin dapat mencetak laporan yang ingin di cetak oleh admin, antara lain (laporan pertanggal, laporan konsultasi. Laporan per penyakit, laporan per jenis kelamin, laporan detail konsultasi)

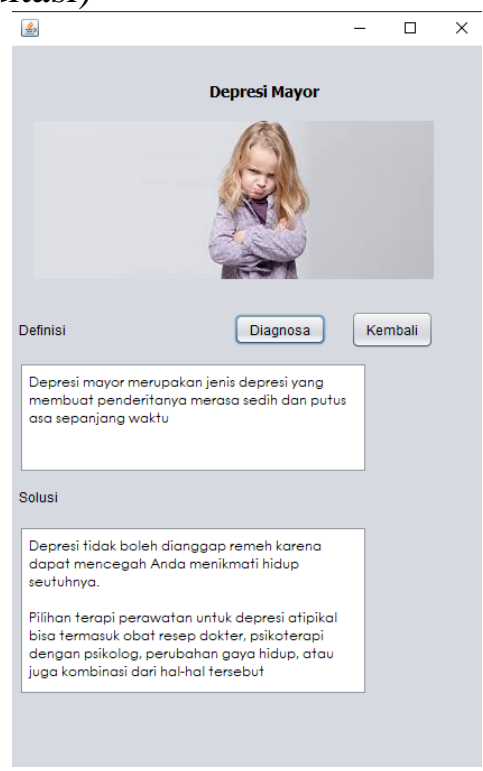

Gambar 10

Pada gambar 10 yang merupakan tampilan informasi perpenyakit. Halaman ini dapat dilihat pengguna setelah melakukan konsultasi ataupun saat memilih menu daftar penyakit dan memilih salah satu penyakit yang ingin dilihat informasinya. 
JURNAL NUANSA INFORMATIKA

Volume 15 Nomor 1, Januari 2021

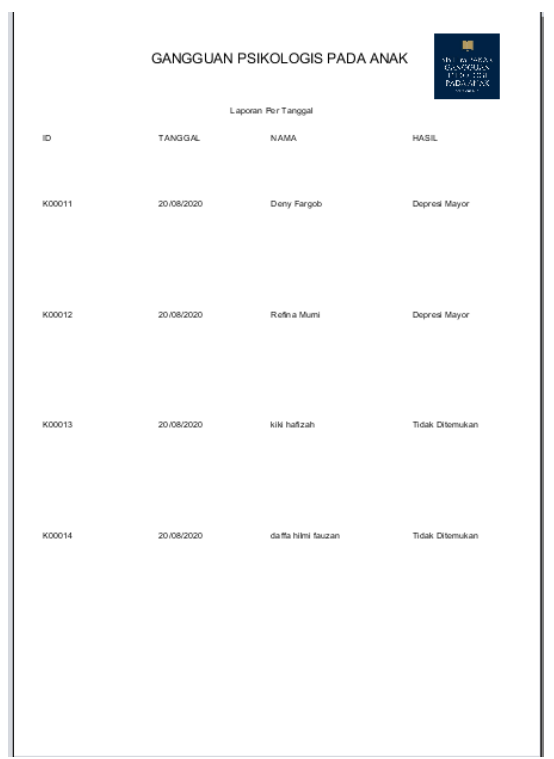

Gambar 11 Laporan PerTanggal

Gambar 10 merupakan tampilan laporan pertanggal yang akan didapat oleh admin ketika admin memilih untuk mencetak laporan pertanggal.

\section{KESIMPULAN}

Berdasarkan hasil analisis dan pengujian terhadap sistem pakar gangguan psikologi pada anak, maka dapat ditarik kesimpulan : aplikasi sistem pakar ini berguna untuk membantu dan mempermudah pengguna dalam memperoleh informasi mengenai gangguan psikologi pada anak khusunya mengenai depresi (depresi mayor, depresi persistent, gangguan bipolar dan depresi psikotis).Dengan menggunakan platform Java maka dapat menganalisis gangguan Psikologis pada anak Dengan adanya program sistem pakar ini diharapkan dapat membantu guru dan orangtua dalam memantau kesehatan psikologi anak.

\section{DAFTAR PUSTAKA}

[1] D. S. Perbawa, W. Laksito, and D. Nugroho, "Sistem Pakar Perilaku Buruk Psikologis pada Anak dengan Metode Forward
p-ISSN : 1858-3911, e-ISSN : 2614-5405

https://journal.uniku.ac.id/index.php/ilkom

Chaining," J. Ilm. SINUS, vol. 10, no. 2, pp. 1-14, 2012.

[2] F. F. Rohman and A. Fauzijah, "Rancang Bangun Aplikasi Sistem Pakar untuk Menentukan Jenis Gangguan Perkembangan pada Anak," Media Inform., 2008, doi:

10.20885/informatika.vol6.iss1.ar $\mathrm{t} 1$.

[3] B. Yuwono, "Pengembangan Sistem Pakar Pada Perangkat Mobile Untuk Mendiagnosa Penyakit Gigi," Semin. Nas. Inform. 2010 (semnasIF 2010), vol. 1, no. Seminar Nasional Informatika semnasIF, pp. 42-50, 2010, doi: 10.1080/13554794.2010.509318.

[4] Haryanto, H. D. Wahyuningsih, and S. Nandiroh, "Sistem Deteksi Gangguan Depresi Pada Anakanak dan Remaja," J. Ilm. Tek. Ind., vol. 14, no. 2, pp. 142-152, 2015.

[5] B. Muhammad Dwi Panji and F. Alifiati, "Hubungan Antara Depresi dengan Perilaku Antisosial pada Remaja di Sekolah," Artikel, 2010.

[6] M. H. Sidiq and Aripin, "Aplikasi Sistem Pakar Gangguan Perkembangan Psikologi Pada Anak Menggunakan Forward Chaining dan Teorema Bayes," Udinus Repo, pp. 1-4, 2015.

[7] R. Nuraini, "Desain Algorithma Operasi Perkalian Matriks Menggunakan Metode Flowchart," J. Tek. Komput. Amik Bsi, vol. 1, no. 1, pp. 144151, 2015. 